\title{
AQUELES QUE DESINSTRUEM!? CARL R. ROGERS E PAUL K. FEYERABEND SOBRE UM TORNAR “MAIS HUMANO" DA EDUCAÇÃO E DA CIÊNCIA
}

\author{
Letícia Jorge $^{1}$ \\ https://orcid.org/0000-0001-5470-6541 \\ Luiz O. Q. Peduzz1 \\ - $\quad$ https://orcid.org/0000-0002-1113-4704
}

\section{RESUMO:}

Visa-se a colaborar para a humanização da formação de professores(as) e de cientistas, bem como da própria ciência, ao se investigar perspectivas da correspondência entre alguns aspectos da teoria da aprendizagem significante de Carl R. Rogers e da epistemologia de Paul K. Feyerabend. Das convergências entre o referencial educacional e o epistemológico, averíguam-se potencialidades de correlação do (i) aprender a aprender do sujeito em processo de aprendizagem com a compreensão de um saber científico em constante desenvolvimento; e (ii) do pluralismo metodológico com o uso de práticas diversificadas tanto para o âmbito pedagógico quanto para o científico. Também são apresentadas sugestôes de implementação das interlocuções entre os aportes teóricos supracitados; evidenciando que as discussões são praticáveis em condições factuais de universidades.

\section{¿¿LOS QUE DESINFORMAN!? CARL R. ROGERS Y PAUL K. FEYERABEND SOBRE VOLVER LA EDUCACIÓN Y LA CIENCIA “MÁS HUMANAS" RESUMEN:}

El objetivo es contribuir a la humanización de la formación de profesores(as) y de científicos(as), así como de la propia ciencia, al investigar perspectivas de la correlación entre algunos aspectos de la teoría del aprendizaje significativo de Carl R. Roges y la epistemología de Paul K. Feyerabend. A partir de la convergencia entre el marco educativo y el epistemológico, se verifican potencialidades de correlación entre el (i) aprender a aprender del sujeto en proceso de aprendizaje y la comprensión de un saber científico en desarrollo constante; y (ii) entre el pluralismo metodológico y el uso de prácticas diversas en el ámbito pedagógico y científico. Se presentan también sugerencias de implementación de las interlocuciones entre los aportes teóricos ya mencionados, evidenciando que las discusiones son posibles en condiciones factuales de universidades.

THE ONES WHO UNINSTRUCT!? CARL R. ROGERS AND PAUL K. FEYERABEND ABOUT AN EDUCATION AND A SCIENCE “MORE HUMANE" ABSTRACT:

The aim is to contribute for the humanization of the teachers and scientists in training, as well as of science itself, by investigating perspectives of correspondence between some aspects of Carl R. Rogers' significant learning theory and Paul K. Feyerabend's epistemology. From the convergences between the educational and the epistemological framework, we can verify the potential correlation between (i) learning to learn from the subject in the

Palabras clave: Formación humana y plural; Ciencia humanizada; Educación científica.

Keywords: Human and plural formation; Humanized science; Scientific education.

\footnotetext{
1 Universidade Federal de Santa Catarina, Campus Universitário Trindade, Florianópolis, SC, Brasil.
} 
learning process with the understanding of scientific knowledge in constant development; and (ii) methodological pluralism with the use of diversified practices for both the educational and scientific spheres. Suggestions for implementing the interlocutions between the aforementioned theoretical contributions are also presented; showing that the discussions are feasible under factual conditions of universities.

\section{UM GUIA QUE (DES)ORIENTA O AVESSO DE UM LINEAR CAMINHAR}

“ 'Vem por aqui' - dizem-me alguns com olhos doces, / Estendendo-me os braços, e seguros / De que seria bom que eu os ouvisse / Quando me dizem: 'vem por aqui'! / Eu olho-os com olhos lassos, / [...] / E cruzo os braços, / E nunca vou por ali... //" (Régio, 1955, p. 108). Poder-se-ia, ainda, exprimir: "[...] Só vou por onde / Me levam meus próprios passos... // [...] // [...] // Como, pois, sereis vós / Que me dareis machados, ferramentas e coragem / Para eu derrubar os meus obstáculos?... //” (Ibid., p. 108-109). “[...] / [...] / Ninguém me diga: 'vem por aqui’! / [...] / [...] / [...] / Não sei por onde vou, / Não sei para onde vou / — Sei que não vou por aí!” (Ibid., p. 110).

Um poema cuja gênese possibilita o evidenciar de ações que fujam à regra, de posturas e práticas que possam se desalinhar e transgredir aos ditames uniformes impostos e exportados pela ideologia social, política, científica, tecnológica, cultural e educacional brasileira. Uma escrita que instiga o necessitar das diversidades, vez que "[...] as humanidades, a filosofia, as artes e o pensamento social estão [...] corroídos por uma [...] 'doença filosófica”” (Feyerabend, 2010, p. 7) que causa um espalhar da criatividade, reflexividade, criticidade e interventividade no próprio ser humano - sendo necessário vigiá-lo e mantê-lo isolado.

Não há benefícios na uniformidade; ela, com efeito, "[...] ameaça o livre desenvolvimento do indivíduo" (Feyerabend, 1977, p. 10). "Por que estamos lutando? [...] É porque, creio, esperamos desenvolver o que há melhor' nos seres humanos" (Rogers, 1978, p. 261). E o que seria "melhor" do que uma formação na qual o indivíduo possa se apreciar "[...] como ser humano imperfeito, dotado de muitos sentimentos, muitas potencialidades[?]” (Rogers, 1978, p. 115). Na qual possa vir a ser tudo que é capaz de ser? Concedendo o devido respeito e a aceitação (não a imposição) a um novo saber e a um outro indivíduo, cujo valor próprio é um direito seu, em uma “[...] aprendizagem [que se dá] sobre nós mesmos em relação aos outros [?] [...]” (Rogers, 1978, p. 116). Não é por isso que se luta? Por uma liberdade ${ }^{1}$ que liberte "[...] o desenvolvimento $e$, portanto, a felicidade [?]. Queremos libertar as pessoas para que elas possam sorrir" (Feyerabend, 1999, p. 191, tradução livre).

Tais considerações levam ao aproximar de uma “[...] recíproca relação eu-tu” (Rogers, 1978, p. 225), isto é, de pessoa para pessoa, na qual a divergência de opiniões, posições e funçóes se faz minimizada e flexibilizada perante a dimensão humana de um encontro entre indivíduos. A discussão se torna propícia tanto para o dilema educacional (e.g., professor(a) sábio(a) e aluno(a) tolo(a)) quanto para o científico (e.g., cientista gênio e cidadão ignorante). Nessa perspectiva, o ponderar sobre o desenvolvimento de um profissional "ser humano", seja docente ou especialista, por meio de processos formativos, centraliza uma necessidade da sociedade.

Por um lado, pode-se ganhar um(a) professor(a) disposto(a) a entender empaticamente as vivências do(a) aluno(a), seus sentimentos, suas limitaçốes, suas potencialidades e rejeiçóes diante dos conteúdos. Pode-se ganhar em diálogo, em envolvimento e em respeito. Essa maneira de agir “[...] pode refletir em práticas mais humanizadas, coerentes com uma filosofia libertadora que preza pela autonomia dos sujeitos [em processos de aprendizagem] e convoca os(as) professores(as) a refletirem sobre a produção de sentido do fazer docente” (Sobreira; Tassigny; Bizarria, 2016, p. 122). De outro lado, se pode ser agraciado com um(a) "cientista renascentista” (Mcbride et al., 2011), cujo ideal incorpora "[...] princípios básicos do humanismo renascentista, nos quais os humanos eram considerados ilimitados em suas capacidades de desenvolvimento" 
(Ibid., p. 466). Em outras palavras, significa conceber um(a) cientista empenhado a compreender e contribuir com uma ampla variedade de campos; e, também, comprometido(a) com o comunicar de saberes para diversos públicos que não sejam exclusivamente seus pares; como não especialistas, não cientistas, estudantes e cidadãos, de uma maneira que se faça avançar no entendimento da natureza.

Além do fato de que em ambos os casos futuros cidadãos emergem para enfrentar o desafio de mundos desconhecidos, também se evidencia, por exemplo, uma particularidade na formação do(a) professor(a) de física e do(a) cientista: "a posse de um conjunto de conhecimentos sobre ciência não [...] adequada [...]. Por isso, a finalidade é fazer com que o estudante fuja da enganosa imagem da ciência como absoluta, completa e permanente" (Rogers, 1978, p. 139). Diversos autores (Miller, 2017; Sena Júnior, 2019) têm dado pormenores mais específicos sobre a maneira pela qual essa meta pode ser alcançada (e.g., melhorias na formação de docentes e de cientistas, nas políticas públicas educacionais, etc.). Porém, dentre as diversas abordagens (e.g., ciência, tecnologia e sociedade (CTS), psicologia ou sociologia da ciência, entre outras) possíveis para a discussão sobre a ciência "[...] os usos da história e da filosofia da ciência (HFC) na educação científica vem sendo recomendado como um recurso útil para uma formação de qualidade [...]” (Forato; Pietrocola; Martins, 2011, p. 29). Nesse sentido, a HFC pode contribuir para o ensino e a aprendizagem de aspectos epistemológicos relacionados à construção do conhecimento científico (Kampourakis, 2017; Raicik, Peduzzi; Angotti, 2018). Ela também possibilita o realce da dimensão humana da ciência - uma vez que ela é um “[...] empreendimento vivo [...]” (Feyerabend, 2010, p. 22), um constructo desenvolvido pelo próprio ser humano, inacabado, imperfeito, concebido com os mais variados devaneios e com muitos planejamentos.

Diante dessas colocações, tem-se como intuito, então, colaborar para uma formação mais humana e plural de professores(as) de física e de cientistas-físicos(as), ao se valer de diálogos entre alguns aspectos da teoria da aprendizagem significante (humanística) de Carl Ransom Rogers e da epistemologia de Paul Karl Feyerabend como subsídio para a discussão da ciência em essência humana e da produção e comunicação do saber científico, por parte desses sujeitos, em maneiras metodologicamente multifacetadas - sejam elas realizadas em laboratórios, em salas de aula ou em outros espaços. Isto, objetivando responder a seguinte questão de pesquisa: como alguns dos pontos de convergência entre aspectos da teoria da aprendizagem significante de Rogers e da epistemologia de Feyerabend podem auxiliar no (re)pensar da formação histórica-filosófica e humanística do(a) docente, bem como do(a) cientista, do campo da física?

\section{AQU(I)-ELES QUE (DES)INSTRUEM DIREÇÕES NÃO PRESCRITAS E, TAMPOUCO, RETILÍNEAS}

Por que Carl R. Rogers (1902-1987) e Paul K. Feyerabend (1924-1994)?! Dado ao reconhecimento, por um número crescente de pesquisadores(as) e educadores(as), de que as abordagens de Rogers (Dasein, 2018; Lima, Barbosa; Peixoto, 2018; Matias et al., 2019; Lopes, 2020) e de Feyerabend (Silva, 2016; Oliveira, 2017; Santos, Fusinato; Gardelli, 2018; Ganhor, Jesusa; Meglhioratti, 2020) atendem à necessidade de uma educação, bem como de uma ciência-física, mais pluralista e humanista.

Ademais, torna-se válido ressaltar que o entrelaçamento entre as principais concepçóes de Rogers e de Feyerabend, embora não existente ou evidenciado na literatura, não se revela do hoje ou do agora; se reflete no ontem e reverbera no amanhã. Ele se faz construir desde meados de 1960 - momento em que se combatia "[...] uma sociedade [...] voltada [...] para a busca de um ideal do máximo de modernização [...], privilegiando os aspectos técnico-racionais, em detrimento dos sociais e humanos [...]" (Campos, 2006, p. 242). O principal foco de propagação desse movimento, basicamente atrelado as manifestações da contracultura, ocorreu na Califórnia; lugar comum a Rogers, que entre 1963 e 1968 expande os interesses pela educação e pela política internacional, e a Feyerabend, que começa a lecionar a partir de 1960 na universidade da Califórnia em Berkeley. É, então, nesse estado - no oeste norte americano - que se “encontram” Rogers e Feyerabend; 
não no sentido de passar a conhecer ou de tomar consciência um do outro, mas de localizar-se em um mesmo espaço de tempo (Fig. 1). Desse cenário, se evidenciam possibilidades de convergências entre algumas ideias desses dois sujeitos que construíram saberes em distintos campos. Um ao tecer críticas às ideias do comportamentalismo (behaviorismo), defendendo a liberdade de aprender sob o viés de uma formação mais humana (Feitosa; Branco; Vieira, 2017; Almeida, 2018), e o outro ao recriminar o predomínio da racionalidade científica (Damasio; Peduzzi, 2015; 2017; Goll et al., 2018), salvaguardando a diversidade de saberes e de procedimentos para a construção do conhecimento.

Figura 1. Esquema que retrata historicamente o "encontro" na década de 1960 entre Rogers e Feyerabend.

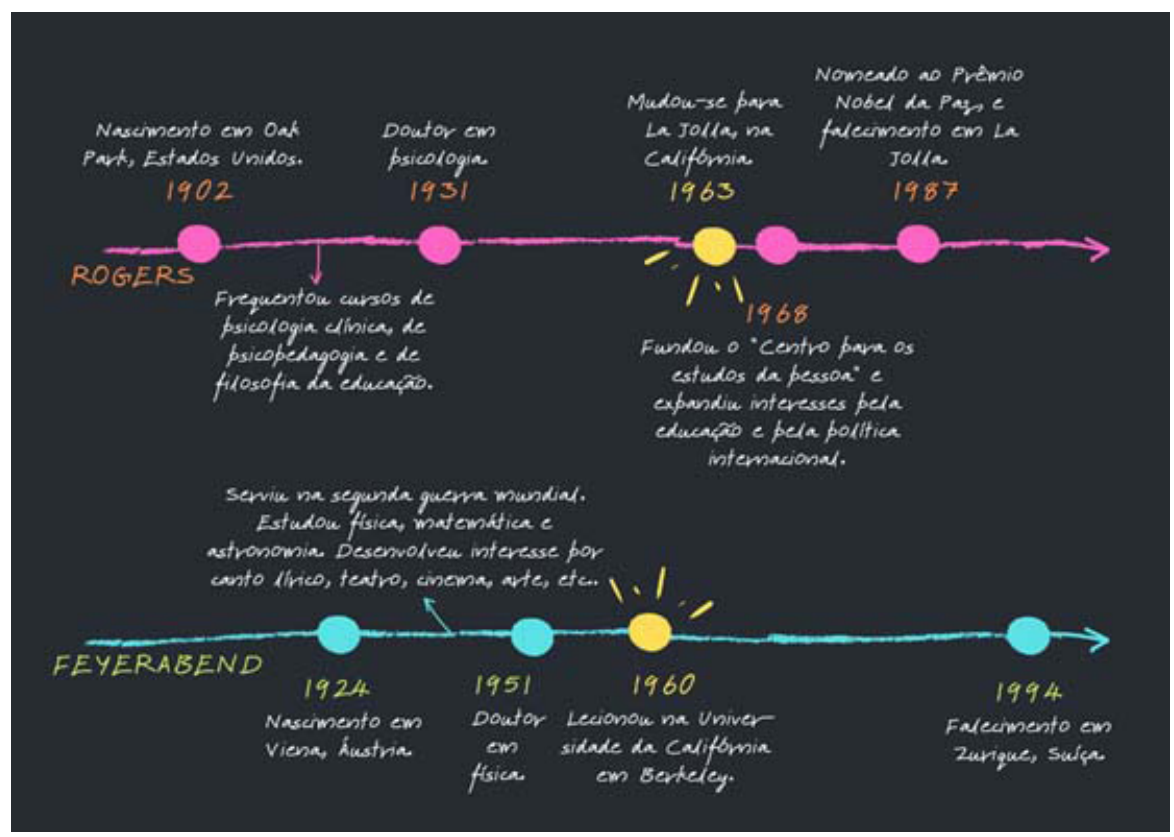

Fonte: Elaboração própria.

Diante disso, não se procurará no referido trabalho, prioritariamente, descrever sobre a vida e obras dos autores - algo já consagrado amplamente na literatura e pelos próprios personagens (Rogers, $1989 ;{ }^{2}$ Feyerabend, 1995); ${ }^{3}$ mas, realçar aspectos a partir de suas vivências e teorias, voltadas à educação e ao conhecimento científico, que possam ser utilizados para o (re)pensar de uma formação e de uma ciência mais diversificada e humana.

Mediante o exposto, parte-se de uma discussão individual das concepções educacionais de Rogers e epistêmicas de Feyerabend para um posterior compor total de questóes entrelaçadas e direcionadas ao âmbito educacional, sobretudo no que tange à potencialidade do debate no ensino de física.

\section{LIBERTANDO E APRENDENDO: UM VIÉS ROGERIANO}

Em um estudo realizado por Kirschenbaum e Jordan (2005), os autores mostram que o status corrente da Abordagem Centrada na Pessoa (ACP), em produções científico-acadêmicas em nível internacional, tem aumentado substancialmente; mais livros e artigos sobre a ACP foram escritos em 17 anos, após a morte do psicólogo, do que nos 40 anos anteriores ao ocorrido. Por meio de um banco de dados virtual (PsycINFO), catalogaram a existência de 84 livros, 64 capítulos de livros e 456 artigos sobre a ACP entre 1946 e 1986 - sem contabilizar livros e artigos escritos por Rogers. Já, nos anos de 1987 a 2004, destacaram 141 livros, 174 capítulos de livros e 462 artigos publicados; evidenciando uma prevalência de trabalhos empíricos que discutiam os resultados da terapia (Kirschenbaum; Jordan, 2005). 
Sob uma perspectiva nacional, Branco e Cirino (2017) apresentaram um panorama de artigos concernentes à ACP publicados no período de 2002 a 2014, a partir do uso de dois bancos de dados virtuais (SciELO e PePSIC). Examinaram 58 artigos sobre a ACP, dos quais ressaltaram alguns resultados: (i) o ano de 2012 reuniu o maior número de publicaçôes (25,8\%), seguido pelo ano de 2014 (22,4\%); (ii) a região nordeste concentrou o maior número de produçóes sobre a ACP no Brasil (41\%), local historicamente marcado por sediar diversos cursos de formação humanista e, também, por receber Rogers e seus colaboradores(as) desde 1977; (iii) houve uma predominância de artigos de cunho teórico (81,1\%); (iv) as temáticas clínicas foram as mais frequentes (37,9\%); (v) 29,3\% dos artigos versaram sobre algo da fenomenologia na ACP; e (iv) a Revista da Abordagem Gestáltica foi o periódico que mais publicou artigos (27,5\%) e, em relação a esse número, Branco e Cirino (2017, p. 5) inferem “[...] que um motivo para isso decorre[u] da recepção do XII Fórum Internacional da Abordagem Centrada na Pessoa [...]” no ano de 2013 em Cumbuco no estado do Ceará, uma vez que alguns trabalhos originários de discussóes e de trocas de experiências ocorridas no fórum foram publicados no ano seguinte, em uma edição especial da revista. $\mathrm{O}$ evento ${ }^{4}$ acontece a cada dois anos em todo o mundo desde 1982, sendo um espaço inigualável para se aproximar, descobrir, apropriar-se da abordagem de Carl Rogers e experimentá-la. Esses e inúmeros outros estudos das ideias de Rogers voltadas à educação atestam a contemporaneidade e pertinência de suas discussões no âmbito nacional.

Rogers (1983, p. 121, tradução livre) considera que “[...] o objetivo da educação [...] [é] a maneira pela qual podemos aprender a viver como indivíduos em processo”. Por indivíduos, entende pessoas psicologicamente maduras, responsáveis por suas açôes, dotadas de iniciativa própria, adaptáveis a novas situaçôes, capazes de resolver problemas a partir de suas próprias experiências, cooperativas, solidárias, flexíveis e criativas. Por conta disso, tece críticas às propostas de educação que levam o(a) professor(a) a ser uma "máquina de ensinar" e o(a) estudante uma "máquina de aprender”, posicionando-se, em vez disso, a favor de uma “[...] abordagem humanística da aprendizagem” (Rogers, 1983, p. 269, tradução livre).

A proposta educacional de Rogers surge da transposição de seus estudos da terapia centrada no(a) cliente - da ACP - para o contexto de sala de aula (aprendizagem centrada no aluno) (Rogers, 1959). A hipótese central da teoria rogeriana é "[...] que o indivíduo tem, dentro de si, vastos recursos para a autocompreensão, para alterar seu autoconceito, para modificar suas atitudes e seu comportamento e que esses recursos podem ser liberados quando se conta com um determinado clima psicológico" (Almeida, 2018, p. 314), isto é, quando se é favorecido um ambiente acolhedor no qual esse despertar pode ser facilitado. Torna-se relevante salientar que a abordagem centrada no(a) aluno(a) proposta por Rogers "[...] pode redundar em insucesso total se se considera isto simplesmente como um novo 'método"' (Rogers, 1978, p. 39). O que o autor expõe é uma maneira; não, necessariamente, “a” maneira de facilitar a aprendizagem.

No que tange ao processo (contínuo) de educar-se, o autor norte-americano discorre sobre as concepções de ensino e de aprendizagem que construiu ao longo de sua experiência como professor: "[...] ENSINAR se me afigurou de tão pouca importância e APRENDER passou a ser enormemente importante para mim" (Rogers, 1978, p. 153). Ele, então, esclarece que à palavra "ensinar” se atribui muitos significados, dentre eles: (i) "instruir" - porém, não desperta interesse por "[...] instruir o outro sobre o que deveria saber ou pensar" (Rogers, 1978, p. 109); (ii) "Comunicar conhecimento ou habilidade” - "[...] por que não ser mais eficiente, usando um livro [...]?”, ironiza (Ibid., p. 109); e (iii) "Fazer saber" - todavia, não tem como propósito "[...] fazer ninguém saber coisa nenhuma” (Ibid., p. 109). A reação negativa de Rogers quanto ao ato de ensinar se pauta na ampla aceitação do pensamento de que a aprendizagem deve ser unidirecional e linear; ocorrendo de um(a) sábio(a) (professor(a)) para tolos(as) (alunos(as)) - com os quais nada se tem a aprender - e sem preocupaçôes para com os interesses dos indivíduos, suas necessidades, seus motivos individuais ou com os locais donde se inserem e se fazem ser. Por conta disso, a atenção de Rogers se direciona ao exercício ou à experiência de facilitar a aprendizagem; não o ensino. 
“Como facilitar aprendizagens de importância? Quais os pressupostos teóricos, básicos, envolvidos?” (Rogers, 1978, p. 159). São questões que perpassam e atravessam por entre princípios que se fazem necessários para a compreensão de uma aprendizagem que se abstraía da experiência usual. Algumas hipóteses, que permeiam o processo da aprendizagem ou a sua facilitação, são discorridas por Rogers $(1959 ; 1978)$.

Primeiramente deve-se considerar que "os seres bumanos têm natural potencialidade de aprender" (Rogers, 1978, p. 159). O potencial é algo intrínseco do indivíduo, que em si existe e reside; é a potência para conduzir seu próprio aprendizado e encontrar seu espaço no mundo, até que, e a menos que, lhe seja possibilitada ser facilitada. É uma aprendizagem "[...] autoiniciada. Mesmo quando o primeiro impulso ou o estímulo vêm de fora, o senso da descoberta, do alcançar [...] e do compreender vem de dentro" (Rogers, 1978, p. 20). Assim, “a aprendizagem autoiniciada [... envolve toda a pessoa do aprendiz - seus sentimentos tanto quanto sua inteligência [...]. Não se trata de aprendizagem 'só do pescoço para cima' ” (Rogers, 1978, p. 164). É um tipo de aprendizagem que integra “[...] os três tipos gerais: cognitiva, afetiva e psicomotora [...]” (Moreira, 2011, p. 138).

Para a aprendizagem autoiniciada ocorrer, parece essencial que o indivíduo entre em contato com algum problema que se configure "real" ou próximo a ele(a); a fim de familiarizar-se com a situação a ponto de resolvê-la (Rogers, 1959). É a partir desse momento que uma aprendizagem significativa pode ser verificada: "[...] quando o estudante percebe que a matéria a estudar se relaciona com os seus próprios objetivos" (Rogers, 1978, p. 160). Nesse viés, o indivíduo "[...] só aprende significativamente aquelas coisas que percebe implicarem na manutenção ou na elevação de si mesmo [...]” (Ibid., p. 160).

Não obstante, diante de novidades há resistências e, de igual modo, "a aprendizagem que envolve mudança na organização de cada um [...] tende a suscitar reações” (Rogers, 1978, p. 160), tornando-se ameaçadora. É uma aprendizagem penosa que está relacionada com certas contradições no interior de cada um, com certas convicçôes, opiniôes, crenças, etc. Contudo, "se eu permito que essa contradição exista, poderei mudar, porque serei forcado a reapreciar alguns dos meus valores” (Rogers, 1978, p. 161).

Há, também, outros fatores, não internos ou intrínsecos do indivíduo, pelo contrário, externos que geram intimidação. Todavia, tal sensação se faz minimizada quando um ambiente de apoio e de compreensão, não gerador de medo de repreensões ou de ridicularizaçóes, é concebido para facilitar a aprendizagem do indivíduo. Assim, "as aprendizagens que ameaçam o próprio ser são mais facilmente percebidas e assimiladas quando as ameaças externas se reduzem a um minimo” (Rogers, 1978, p. 161).

Um cenário no qual haja “[...] confronto experiencial direto com problemas práticos - de natureza social, ética e filosófica ou pessoal - e com problemas de pesquisa” (Rogers, 1978, p. 163) também se torna uma maneira de facilitar uma aprendizagem ativa; precipuamente "[...] quando o aluno participa responsavelmente do processo" (Ibid., p. 163), contribuindo com o pensar de recursos para o próprio aprendizado e com o formular de problemas que lhe dizem respeito, escolhendo suas próprias direçóes e vivendo as consequências das mesmas. Isto o leva a uma aprendizagem autodirigida - algo que, para muitos(as), engloba um ziguezaguear sem rumo que leva a modelos imprevisíveis e conduz ao caos. Entretanto, o que se denomina "caótico", aqui, nada mais é do que uma variedade de modos de aprender, de (re)encontros consigo mesmos, de aceitamentos, anseios e aproximaçôes para com os outros.

Ademais, em uma aprendizagem autodirigida também é possível uma “[...] transição entre a completa liberdade para aprender seja o que for, de interesse, e a aprendizagem relativamente livre, mas situada dentro dos limites de alguma experiência institucional” (Rogers, 1978, p. 136) ou da estrutura do currículo e das unidades específicas de estudo, ao se fazer uso de contratos e de acordos mútuos entre o(a) professor(a) e o(a) aluno(a). Como, por exemplo, (1) decidir se o contrato será de curto ou longo prazo; (2) desenvolver um formato geral para o contrato, em termos de planejamento; (3) reunir materiais e informaçôes sobre recursos que possam ser utilizados pelo(a) aluno(a); (4) realizar algumas sessóes de feedback com o(a) aluno(a) sobre seu progresso; e (5) explicitar no contrato como ele(a) será avaliado(a) (Rogers, 1983). Diante disso, verifica- 
-se a existência de certa organização nessa maneira de se aprender; vez que o(a) aluno(a) tem que ser capaz de pensar, estruturar, implementar e avaliar o projeto de sua própria aprendizagem. Assim, "a independência, a criatividade e a autoconfiança [podem ser] facilitadas [...]” (Rogers, 1978, p. 164).

Para a viabilidade da experiência em aula é imprescindível que o(a) professor(a) (Sobreira; Tassigny; Bizarria, 2016), ou melhor conceituando, o(a) facilitador(a) da aprendizagem seja o(a) corresponsável perante a responsabilidade do(a) aluno(a) de tornar-se o centro de sua própria aprendizagem; algo concebível, uma vez que a base filosófica do(a) facilitador(a) envolve a confiança nos indivíduos que do processo participam. Por conta disso, ele(a) procura considerar "[...] a si mesmo como recurso flexivel a ser utilizado pelo grupo" (Rogers, 1978, p. 165) ou individualmente.

Torna-se válido salientar que essas colocações não excluem o papel do(a) professor(a) nem fundamentam sua substituição no campo da educação por outros profissionais, os quais têm como intuito assegurar que alunos(as) "absorvam" um particular e comum conjunto de concepçóes consideradas essenciais para o molde e a sobrevivência em uma sociedade não tolerante ao diferente. Portanto, para Rogers (1983), o(a) facilitador(a) não se torna marginalizado ou colocado fora de cena; ele(a) continua existindo e contribuindo para a aprendizagem do(a) aluno(a) mesmo que não seja o(a) protagonista da obra.

Quando o(a) facilitador(a) da aprendizagem aceitar as irregularidades de seus alunos e as suas - sendo “[...] uma pessoa, não uma personificação sem rosto de um requisito curricular ou um tubo estéril através do qual o conhecimento é passado de uma geração para a outra” (Rogers, 1959, p. 237, tradução livre) -, se terá uma "[...] imagem da pessoa que está a aprender, continuamente, como aprender" (Rogers, 1978, p. 270) e um cenário favorável à construção de uma aprendizagem significativa.

Eis o meu modelo teórico da pessoa que emerge [...] do melhor que possa haver em educação [...] - uma pessoa que funcione livremente em toda a plenitude das suas potencialidades organísmicas; uma pessoa que será realista, autoengrandecedora, socializada e apropriada em seu comportamento; uma pessoa criativa, cujas específicas formas de comportamento não são facilmente previsíveis; uma pessoa sempre em mudança, sempre em desenvolvimento, sempre a descobrir-se a si mesmo e ao que há de novo em si, a cada instante sucessivo do tempo. (Rogers, 1978, p. 276)

Ao que foi descrito, Rogers (1978) acentua ser um objetivo teórico; um ponto final do crescimento de um indivíduo que, por ora, não existe. Pode-se, em um máximo, buscar caminhar em tal direção para se reconhecer que o único ser humano "educado" é aquele "[...] que aprendeu a aprender; [...] que aprendeu como se adaptar e mudar; [...] que percebeu que nenhum conhecimento é seguro, [e] que apenas o processo de busca de conhecimento fornece uma base para a segurança” (Rogers, 1983, p. 120, tradução livre), sobretudo, em um mundo mutante. Um mundo que se (re)transforma a cada época, década, semana ou em cada piscadela. Um mundo no qual "[...] o objetivo da educação [...] seja facilitar as mudanças e o aprendizado" (Ibid., p. 120, tradução livre).

\section{ABRINDO E CONHECENDO: UM OLHAR FEYERABENDIANO}

O mundo; aquele espaço circunscrito, repleto de sujeitos, de seres vivos e "não vivos", de cenários estonteantes e, também, atordoantes, de conhecimentos e discursos, de opções, contradições e de multiformes tradiçôes. "Devemos realmente acreditar que as regras ingênuas e simplistas que os metodologistas adotam como guia são capazes de explicar esse 'labirinto de interaçóes'?” (Feyerabend, 1977, p. 19).

A educação científica, por exemplo, tal como levada a efeito em muitos materiais e instituiçôes educacionais, engessa e distorce a ciência ao unificar os seus múltiplos e variados procedimentos, ao esquecer erros, inibir devaneios e dissolver entrelaçamentos. Ela se coloca em confronto com "[...] o cultivo da humanidade, único procedimento que [...] pode produzir seres humanos bem desenvolvidos [...]” (Feyerabend, 1977, p. 22), despossando, assim, de uma face mais humanista. "A tentativa de fazer crescer a liberdade [...] e a [...] de 
descobrir os segredos da natureza [...] implicam, portanto, rejeição de todos os padróes universais e de todas as tradições rígidas" (Feyerabend, 1977, p. 22) que se impóem a pesquisas ou a seres humanos independente do contexto em que são produzidas ou se encontram inseridos, respectivamente. Isto propicia para o pensar de uma "[...] metodologia anárquica e de uma correspondente ciência anárquica” (Feyerabend, 1977, p. 23) discordante de uma epistemologia científica que encobre a complexidade e a exuberância das práticas científicas em proveito de um único e comum modo de se construir conhecimento.

$\mathrm{Na}$ literatura evidenciam-se pesquisas que tratam da abordagem anárquica de Feyerabend como assunto sumamente de potência (Damasio; Peduzzi,2015; Santos; Fusinato; Gardelli, 2018). Há, também, aquelas que demonstram o referencial feyerabendiano como uma matéria de muitas brancuras (GOLL et al., 2018), seja na ausência de seu uso no cenário pedagógico ou no epistemológico. Silva (2016), a título de exemplo, realizou um levantamento de artigos, relativos ao tema da história e filosofia da ciência (HFC) e suas relaçóes com a educação científica, em 5 periódicos da área do ensino de ciências entre o período de 1979 a 2014 . O autor identificou 141 trabalhos; sendo 5 deles referentes à abordagem epistemológica de Feyerabend no âmbito educacional. Damasio e Peduzzi (2017), sob outra perspectiva, desenvolveram uma revisão bibliográfica, a partir da produção científica-acadêmica de 11 programas de pós-graduação em nível nacional entre os anos de 2005 a 2014, para averiguar os modos pelos quais a HFC é abordada na educação científica. Os autores elegeram 33 dissertações de mestrado e 8 teses de doutorado. Dentre as pesquisas, apenas uma, de mestrado, mencionou Feyerabend. Essas revisóes revelam "[...] um esquecimento/invisibilidade das ideias feyerabendianas e suas respectivas contribuições para pensar a educação científica no contexto brasileiro” (Silva, 2016, p. 14) e, consequentemente, uma necessidade de contribuição de trabalhos para o respectivo campo.

Diante disso, o uso do anarquismo epistemológico ${ }^{5}$ enquanto aporte teórico no uso da história da ciência em sala, por exemplo, “[...] facilitaria na compreensão da ciência como sendo construída por seres humanos [...]” (Santos; Fusinato; Gardelli, 2018, p. 3), visto que ela se faz existir a partir dos pensamentos e devaneios, suscetíveis constantemente a aprimoramentos e questionamentos, de indivíduos. Ela é imperfeita, inacabada, não neutra, influenciada, singular e particular de cada época; fatos que também reforçam o sentido humano da ciência e sua imprescindibilidade por "[...] pessoas que sejam adaptáveis e inventivas" (Santos; Fusinato; Gardelli, 2018, p. 3). Dado que, de acordo com a análise da história da ciência, "as ideias de que os cientistas costumam valer-se para apresentar o conhecido e avançar rumo ao desconhecido raramente estão em estrita concordância com as injunçôes da lógica ou da matemática pura [...]” (Feyerabend, 1977, p. 458), embora uma combinação sutil, mas cuidadosamente dosada, de inventividade e controle sejam componentes assinalados para o êxito da ciência.

É notável, ainda, destacar que “[...] o trabalho de um cientista, na visão de Feyerabend, é muito mais difícil que na ciência vista sob a óptica metodológica de um racionalista” (Damasio; Peduzzi, 2017, p. 344), pois o(a) pesquisador(a) que "[...] adotar metodologia pluralista" (Feyerabend, 1977, p. 40) verá que o conhecer de diversificadas práticas e o selecionar - dentro delas - de procedimentos mais adequados para se alcançar um dado objetivo frente à produção de conhecimentos é tarefa deveras complexa; porém, sumamente gratificadora e libertadora perante uma multiplicidade de opçóes e mundos.

Vale evidenciar, diante disso, que o fato de cada cientista manter em si aspectos individuais (e.g., interesses e objetivos) e coletivos (e.g., tradição e seus próprios regimes sociais), que podem contribuir para o seu empenho na busca por novos modos de construir saberes e de solucionar problemas, não resulta na conjectura de uma produção de conhecimentos onde "tudo vale"; não havendo, portanto, relevância sobre como proceder na ciência ou o que considerar como prioridade no processo investigativo. Esta é a interpretação dos mais “encarniçados racionalistas” que “[...] veem claro que só há um princípio que pode ser defendido em todas as circunstâncias e em todos os estágios do desenvolvimento humano” (Feyerabend, 1977, p. 34). Feyerabend, então, intitula cinicamente esse "princípio" de "tudo vale" - embora não seja amparado por ele mesmo (Feyerabend, 1977) - na perspectiva de contra-argumentar que se for para atribuir algum princípio 
universal ao processo de pensar e fazer científico, o único passível de demonstrar a riqueza de seus detalhes e a dinamicidade de suas açôes metodológicas, com embasamento na história da ciência, seria o do "tudo vale".

“Tudo vale”, para Feyerabend, não é impor ou aceitar qualquer coisa. Não é transformar a pesquisa em arbitrária e desgovernada. É conscientizar-se de que existem enésimos saberes e multifacetadas ciências, cada qual com padrôes e métodos válidos ao seu campo específico que não podem ser universalizados para todos os outros cenários, dado as limitaçóes do pensar e fazer da tradição na qual esses procedimentos foram criados - não sendo aplicáveis, em virtude disso, a outros contextos com valores e interesses divergentes. No entanto, não significa ponderar que não há necessidade de estabelecer contato com outras culturas, já que o que é valido para uma pode não ser para a outra. Muito se pode aprender com elas, caso se tenha esse processo como intuito; um olhar pode compreender um outro ver, um pensar pode perceber um outro conceber e um operacionar pode começar a se transformar.

Portanto, "tudo vale" é analisar dentro de uma vasta gama de possibilidades o que de melhor pode caber a investigação a fim de minimizar as limitações metodológicas e do pensamento originários da tradição correspondente à qual pertence para fazer progredir o conhecimento. É “[...] passar a praticar a ciência de maneira diversa e verificar o que vem a ocorrer" (Feyerabend, 1977, p. 450) ou surgir dela, sejam problemas, prioridades, procedimentos ou soluçôes. A pretexto disso, “[...] um método que estimule a variedade é o único método compatível com a concepção humanitarista” (Feyerabend, 1977, p. 57).

A crítica, até então, tecida por Feyerabend relaciona-se à unidirecionalidade de pensamentos, de comportamentos e de procedimentos na produção do conhecimento científico alinhados, por vezes, a uma tradição que se mantém una ou intacta graças à observância de regras rígidas que, até certo ponto, podem alcançar êxito; mas, posteriormente, podem se mostrar insuficientes e restritas. "Todas as metodologias têm limitaçốes [...]” (Feyerabend, 1977, p. 450) e se uma possibilidade se mostra insustentável, então, outra pode ser investigada. Porém, "ao invés de admitirem que [...] não são mais capazes de avançar no conhecimento, os cientistas costumam dizer que finalmente chegaram à verdade” (Feyerabend, 1999, p. 107, tradução livre).

Nessas circunstâncias, o que mais se pode fazer além de segui-la? É “[...] claro que não é verdade que temos que seguir a verdade. A vida humana é guiada por muitas ideias. A verdade é uma delas. Liberdade e independência mental são outras. [...] Minha crítica à ciência moderna é que ela inibe a liberdade de pensamento" (Feyerabend, 1999, p. 182-183, tradução livre). Embora, em tempos passados, tenha estado na vanguarda da luta contra o autoritarismo e a superstição, proporcionando uma maior liberdade intelectual em relação às crenças religiosas e à libertação da humanidade das formas antigas e intransigentes de pensamento, a ciência, contemporaneamente, "[...] tornou-se rígida [...] [e] deixou de ser um instrumento de [...] libertação [...]” (Feyerabend, 1999, p. 182, tradução livre).

Talvez, esse efeito de petrificação e de inflexibilidade da ciência tenha, até certo ponto, se tornado um dos fatores contribuintes para a expansão de uma dimensão anti-intelectual e anticientificista brasileira (Sena Júnior, 2019), ao ignorar, desqualificar, depreciar ou rejeitar saberes e, sobretudo, seres situados em campos relativamente marginais à academia científica. É razoável pensar que os divergentes conhecimentos não necessitam ser aceitos ou acordados por outras culturas; basta, com excelência, a cada uma delas salvaguardar-se equitativamente o direito de existirem.

Feyerabend, então, “[...] não afirma que todas as tradições ou suas crenças são igualmente verdadeiras ou igualmente corretas [...]” (Kusch, 2016, p. 109, tradução livre). Essa função cabe ao relativismo filosófico; uma vertente do relativismo que o autor austríaco não defende (Farrell, 2003; Feyerabend, 2010). Ao invés disso, assume que direitos iguais devem ser concedidos às diferentes tradiçôes, que dão sentido à vida das pessoas, dentro de uma comunidade. Deve-se “[...] respeitar seus modos de vida [...]" (Feyerabend, 2010, p. 52). Ao ponderar acerca disso, Feyerabend não acaba se aproximando de um relativismo absoluto, mas de um relativismo político (Damasio; Peduzzi, 2017) - dado a ideia de que se deve outorgar a concessão de direitos a membros de uma 
sociedade independentemente das tradições a que pertençam. Assim, para o epistemólogo austríaco “[...] o relativismo [...] não é sobre conceitos [...] e sim sobre relaçôes humanas” (Feyerabend, 2010, p. 103).

Portanto, quando Feyerabend discorre sobre relativismo ele não o faz na perspectiva de o considerar como um todo instituído que envolve a vasta gama de versões, concepçóes, significaçôes e distribuições puritanas. Ele fala em "relativismos", em “[...] variedade de pontos de vista” (Feyerabend, 2010, p. 28), que podem auxiliar para a tentativa de perceber e compreender o fenômeno da diversidade cultural. Dentro desse viés, o autor discursa sobre três tipos de relativismo: o (i) prático; o (ii) democrático e o (iii) epistêmico.

No relativismo prático o intercâmbio entre povos, com distintos costumes, regimes de conhecimento e conceitos, pode se tornar proveitoso e auspicioso. É um tipo de relativismo que suscita oportunismo, pois "[...] admite que uma cultura estrangeira possa ter coisas que mereçam ser assimiladas, toma o que pode usar [dela] e deixa o resto intocado" (Feyerabend, 2010, p. 106). Para isso, leva-se em conta dois componentes: um "factual", relativo a como a tradição em estado de interlocução com a correspondente de um(a) cientista, por exemplo, pode exercer ou sofrer influências e vice-versa; orquestra-se, nesse caso, possibilidades e potencialidades entre os campos. E o outro "normativo", referente a como o encontro entre as tradiçóes deve tecer influências de uma em outra, levando em consideração que cada uma é regida por interesses e regras, válidas somente para os seus domínios, que podem em maior ou menor grau estarem abertas a modificaçôes suscitadas pelas novas relaçôes. Assim, o relativismo prático é um desbravar, um buscar e selecionar de oportunidades em mundos distintos de territórios vizinhos. E, "certamente, não devemos descartar desde o início que existam coisas que podemos aprender com outras culturas” (Kusch, 2016, p. 109, tradução livre).

Tal processo, bem como expõe Feyerabend, não resulta em um "[...] conflito entre a prática científica e o pluralismo cultural" (2010, p. 50). Não há confronto quando há respeito: salvo o momento em que "[...] a boa ciência é transformada em má ciência [...]” (Feyerabend, 2010, p. 50), isto é, quando os resultados considerados locais e preliminares e os métodos interpretados como maneiras práticas e, por vezes, irrestritas de proceder - sem deixar de ser científicos - "[...] são congelados e transformados em medidas de tudo o mais [...]" (Feyerabend, 2010, p. 50). O desacordo, nesse caso e segundo Feyerabend, não é para com a própria ciência, dado que "[...] o pressuposto de toda a ciência é que seja capaz de explicar alguma coisa, para além das explicaçôes oferecidas pelo senso comum ou por outros ramos de saber [...]” (Sena Júnior, 2019, p. 24); isto, contemporaneamente, ela o faz muito bem quando não limitada pelas suas próprias barreiras culturais. A crítica, então, é para com alguns filósofos da ciência que sustentam uma epistemologia científica que oblitera a complexidade e riqueza de suas práticas, asseverando a superioridade dessa forma de produção de conhecimento e todas as suas prerrogativas. Por conta disso, o autor pondera "[...] que nem valores, nem fatos, nem métodos podem corroborar a afirmação de que a ciência e as tecnologias que nela se baseiam [...] se sobrepóem a todos os outros empreendimentos" (Feyerabend, 2010, p. 33).

No que tange ao relativismo democrático, destaca-se que este fornece subsídios para que cada sociedade ou povo, imbricado em sua obra de base jurídica ou de bem-estar social, possa vivenciar maneiras peculiares de conceber, ver e interpretar o mundo. Não há porque presumir que a universalização de teorias ou de pontos de vista sejam válidos em todas as circunstâncias (e.g., culturas, civilizaçôes, etc.) e sejam, sobretudo, compulsórios a todos. Por isso, a enunciação de Feyerabend na defesa de um relativismo democrático que combate a unicidade das tradiçôes e das imposiçôes "[...] de cima para baixo por uma 'gang de intelectuais radicais" " (Abrahão, 2015, p. 215). O relativismo, então, "é democrático porque suas premissas básicas são (em princípio) debatidas e decididas por todos os cidadãos" (Feyerabend, 2010, p. 74); tanto especialistas quanto não especialistas. A participação de todos na tomada de decisões “[...] pode levar à descoberta de que existem muitas maneiras de ser no mundo, de que as pessoas têm o direito de usar os caminhos que as atraem e que, usando-os, podem levar uma vida feliz e satisfatória” (Feyerabend, 2010, p. 78).

Um controle científico da democratização da ciência unicamente por peritos ou cientistas, por outro lado, redunda em um elitismo intelectual intimidador perante os periféricos ao âmbito acadêmico-científico, 
os quais não suscitam valores de suas próprias tradições por serem diferentes das do dogma dos experts que, em certa medida, logra êxito. Tal alegação revisita a tese feyerabendiana de crítica à base do racionalismo ocidental de superioridade da ciência; não sendo esta, por unanimidade, melhor do que todas as outras alternativas e, tampouco, composta por evidências indubitáveis ou privada de questionamentos.

Por conseguinte, “[...] o relativismo democrático é contrário à imposição de uma forma de vida sobre outras [...]” (Abrahão, 2015, p. 214), antagônico aos ditames rígidos de um serem implantados e instalados em outros, adverso ao predomínio e ao fortalecimento de um único modo de conhecimento. Nesse sentido, o argumento feyerabendiano envolve a problematização de que "[...] o valor mais importante em uma sociedade democrática é a [participação e] decisão dos cidadãos [...]” (Abrahão, 2015, p. 215) afetados pelo processo.

Para o relativismo epistêmico há diversos modos de viver e de organizar experiências que oferecem descriçốes próprias e singulares do mundo. Cada uma delas " [...] pode originar um pensamento abstrato que, por sua vez, pode se dividir em teorias abstratas rivais. As teorias científicas, para dar um exemplo de nossa própria civilização, se ramificam em várias direçôes, usam conceitos [...] e avaliam eventos de maneiras diferentes" (Feyerabend, 2010, p. 93).

Nesse tipo de relativismo destacam-se duas questóes primordiais. Primeiro, que existem possibilidades de soluçôes para o conflito entre a compreensão de "[...] que nossos recursos para avaliar afirmações epistêmicas são, em certo sentido, limitados” (Ashton, 2019, p. 589, tradução livre) e a “[...] de que nossas crenças equivalem a conhecimento e, portanto, não são drasticamente comprometidas por nossos recursos epistêmicos limitados” (Ibid., p. 589, tradução livre). Isto, por sua vez, envolve o entendimento da própria posição epistêmica do indivíduo que se encontra em uma linha tênue entre a tolerância - respeitosa, aberta a interação entre culturas - e a resistência - impregnada, debruçada sobre velhos hábitos de uma tradição específica. E, a segunda questão, que pode “[...] permitir-nos desenvolver a virtude intelectual da humildade" (Ashton, 2019, p. 604, tradução livre) ao invés de promover o "progresso" da arrogância intelectual. Com isso, passa-se a lidar "[...] não apenas com questôes intelectuais, mas também com sentimentos, fé, empatia, e muitas outras agências ainda não catalogadas e batizadas pelos racionalistas” (Feyerabend, 2010, p. 95).

\section{CONVER(SAS)-GÊNCIAS: O QUE PODE A COMPLEMENTARIDADE ENTRE ALGUMAS IDEIAS DE ROGERS E FEYERABEND NA FORMAÇÃO DE PROFESSORES E DE CIENTISTAS? PODE?!}

Ao se considerar certos aspectos da teoria educacional de Rogers e da epistemologia de Feyerabend, averíguam-se emaranhados de possibilidades e potencialidades de utilização destes saberes para um pensar da educação científica. Um pensar que desconstrua a postura absoluta e imperiosa que se tem comumente do processo de aprender e da construção da ciência. Um pensar que percorra um caminho multidirecional e multicultural; sem a obsessão, exclusivamente, de um resultado final. Um pensar que expanda o olhar e o respeitar.

Contudo, parece a muitos difícil proporcionar liberdade de aprender aos estudantes do atual sistema educacional brasileiro, sendo que "[...] há indivíduos e grupos que se apegam a [...] a rígidos pontos de vista sobre o que a escola ou a universidade devem ser, além de temerem, profundamente, a liberdade de pensar, de escolher e de agir [...]" (Rogers, 1978, p. 297) de seus alunos(as). Tantos são os limites exteriormente impostos para a liberdade de aprender (e.g., a duração do semestre letivo, o conteúdo programático, a pressão institucional, etc.); precipuamente, no nível universitário. "Como podem ser livres os estudantes se o curso é previamente estabelecido, sem nenhuma possibilidade de escolha para eles?” (Rogers, 1978, p. 43). Certa liberdade pode ser cedida, por exemplo, a partir da construção de um acordo mútuo (e.g., uso de contrato didático) entre aluno e facilitador da aprendizagem ao se levar em consideração os objetivos da instituição e do próprio sujeito.

Em uma situação "real”, a ideia da convergência entre certos aspectos dos trabalhos de Rogers e de 
Feyerabend seria viável, à título de exemplo, em uma disciplina de um curso de física que realizasse análises históricas e/ou epistemológicas dos desenvolvimentos conceituais das teorias físicas. Em uma ementa em que constassem discussões a partir da Grécia (século VI AEC) - algo inteiramente razoável dado o fato de muitos(as) historiadores(as) da ciência situarem nos gregos o início da ciência ocidental - poder-se-ia reservar um espaço para o debate de conhecimentos antecedentes a esse período e pouco mencionados na história da ciência. Uma alternativa que pode contribuir com reflexóes significativas sobre esse tema, ao se fazer uso de um relativismo prático, seria conhecer, explorar e analisar os limites e as perspectivas de explicaçóes dadas por culturas e povos mais remotos (e.g., tradição mesopotâmica, egípcia, chinesa, indiana, etc.) sobre os fenômenos da natureza e do funcionamento do mundo. Com esse processo, seria possível evidenciar a evolução do pensar e do fazer ciência como algo em constante desenvolvimento, inacabado, imperfeito e mais humano. Gera-se disso, também, uma oportunidade para que o facilitador da aprendizagem possa ressaltar a importância de um continuar a aprender a maneira de aprender; de não se prender, mas, de se permitir estender a uma busca por um outro novo saber. De tal discussão surge, ainda, uma distinta implicação: a possibilidade de desnaturalização do currículo - (des)enrijecido a partir do intercâmbio com outros mundos.

Outra interlocução entre os autores, pensada para a disciplina histórica hipotética e possível de ser estendível para outras de cunho didático (e.g., visando o desenvolvimento de práticas pedagógicas mais diversificadas e plurais), envolveria o aproximar da relação "eu-tu”, isto é, do(a) facilitador(a) e do(a) estudante em um ambiente aberto e receptivo às inserçốes e discussóes de suas culturas, crenças e concepçôes - na perspectiva de um relativismo democrático que outorga a todo e qualquer indivíduo o direito de opinar e de participar. Isto, não necessariamente infere que toda e qualquer ponderação será imediatamente imposta e aceita sem ser coletivamente questionada e analisada. Não se conduz, também, a ideia de que a existência de um professor em sala não se faz necessária por conta de uma "malvista" liberdade proporcionada; fala-se sobre a importância do relacionamento entre humanos não de indivíduos isolados e superdotados - caso contrário, não haveria porque se debater sobre um sistema de ensino que não se sustentaria.

Um exemplo significativo do que fora exposto se faz expresso no trabalho de Aires e colaboradores(as) (2015). Os autores e as autoras implementam uma estratégia pedagógica, embasada na teoria da aprendizagem significativa de Rogers, com 18 alunos(as) do 2o ano do curso Técnico em Informática - sendo a atividade mediada por 4 estudantes (facilitadores ou facilitadoras) do 5 o período do curso de licenciatura em física do Instituto Federal de Educação, Ciência e Tecnologia do Sertão Pernambucano, Campus Petrolina. A proposta envolve a divisão da turma em 3 grupos para a discussão da temática dilatação dos sólidos. À cada grupo se designou, ao menos, um(a) facilitador(a) - disposto(a) a contribuir e auxiliar quando preciso. Os(as) facilitadores(as) buscaram tornar-se menos invasivos(as) possíveis nas escolhas e debates dos(as) estudantes, a fim de descontruir a ideia de autoridade do(a) professor(a) ou pesquisador(a), criando assim um ambiente de autoanálise, descobrimento e respeito que proporciona a autonomia (i.e., uma aprendizagem autodirigida) dos(as) alunos(as) na busca e construção do saber físico. Diante da proposta de Aires e companhia (2015), emerge o devanear sobre uma outra implicação da relação entre concepções rogerianas e feyerabendianas no ensino de física: a quebra da hierarquização do ser, do aprender e do saber.

Quanto ao indagar sobre quais conhecimentos, além do científico, deveriam constituir a formação do(a) professor(a) de física, não cabe uma lista de saberes comumente imposta como resposta. As pessoas, as condiçốes de aprendizagem, os seus objetivos, os das instituições, o lugar no qual se localizam, o tempo de preparação e de execução das aulas e o conteúdo programático de cada disciplina são variados. Deve-se buscar conhecer a realidade local para se estruturar um espaço e um contrato plausível de ser efetivado por ambos os lados, tanto pelo(a) facilitador(a) quanto pelo(a) aluno(a).

Isto acentua o fato de que as interseçôes entre aspectos do referencial educacional de Rogers e do epistemológico de Feyerabend são praticáveis em condiçóes factuais de universidades. Trata-se, portanto, de uma alternativa que "poderia adaptar-se, sem maiores dificuldades, ao ensino da física, numa faculdade 
de normas extremamente rígidas [...]" (Rogers, 1978, p. 65) que, em maior parte, apresenta saberes sobre a ciência como um conjunto fixo de conhecimentos estruturados à margem do contexto histórico e sócio-econômico-cultural (Forato; Pietrocola; Martins, 2011). É preciso ressaltar, todavia, que a ideia se constitui em um iniciar de pequenas inserçôes em disciplinas de cunho histórico e/ou epistemológico, presentes em cursos de licenciatura da área da física, que possam promover, quando possível, discussóes sobre saberes locais e não necessária ou exclusivamente ocidentais. Não se trata, portanto, de uma revolução imediata e radical no âmbito educacional. Não há abandono dos padróes acadêmicos ou do rigor universitário. Não há descaso para com os saberes postos. O que se frisa é a necessidade de encontros. Cenários nos quais "esbarros propositais" possam contribuir para ressaltar a relevância de se aprender sobre o que caracteriza a ciência como um empreendimento humano por meio das relações entre variados sujeitos.

Por que, então, não extrapolar as fronteiras ou irromper barreiras quando, na perspectiva de uma disciplina de cunho histórico e na possibilidade do uso de um relativismo prático, muito se pode aprender com distintas culturas? Por que privar conhecimentos de dialogar e se comunicar com outros? Por que coroar um único campo? São questões a inquietar para alvoroçar. É inegável a relevância da ciência para os "[...] membro[s] da tribo de intelectuais ocidentais [...]" (Feyerabend, 2010, p. 91) no que tange ao propiciar de explicaçốes mais plausíveis e para além das formas antigas e rígidas de pensamento. Porém, não se compreende ou se discute a importância que tem para povos que não fazem parte dessa tradição - que nega, por vezes, o caráter racional de todas as formas de conhecimentos que não se regulam pelos seus princípios epistemológicos e pelas suas práticas metodológicas.

Vale realçar que o que se está a defender não é, em absoluto, a substituição ou a exclusão da ciência nos mais diversos níveis de ensino. O que se discute é a sua permanência e a possibilidade de fazê-la coexistir com outros modos de viver e de pensar, já que em "[...] uma sociedade pluralista como a nossa, uma opção humanística seria oferecer oportunidade de sobreviver” (Rogers, 1983, p. 250, tradução livre). É, portanto, trazer a potencialidade desses outros campos para que se possa ressaltar as limitaçóes do conhecimento científico ao invés de serem obliteradas, em vista de uma constante busca de fazer crescer o saber. Nessa perspectiva, é importante que o(a) professor(a) em formação, por exemplo, compreenda os conceitos científicos sem, contudo, tê-los como inexoravelmente verdadeiros em suas vidas, uma vez que todo conhecimento é incerto e provisório (Rogers, 1983).

Em conformidade com a discussão, Feyrabend (1977, p. 465) atenta para o fato de que o(a) estudante em formação pode estudar "[...] as ideologias mais importantes em termos de fenômenos históricos [...]" e, ao fazer isso, entender "[...] a ciência como [um] fenômeno histórico e não como o único e sensato meio de enfrentar um problema”. Uma forma de se tecer aproximações a isso no ensino é considerar, dentro das disciplinas de cunho histórico e/ou didático sugeridas, tanto o conhecimento local quanto o ocidental, ponderando as limitaçóes e perspectivas de cada um, para pensar o que melhor se adequa aos costumes das comunidades que estão em processo de interlocução cultural.

Por isso, o que se debate aqui não deve ser interpretado como um esboço "[...] de uma nova ordem social que deve ser imposta às pessoas hoje com a ajuda da educação [...] e de slogans melosos (tais como 'a verdade irá libertá-los') [...]" (Feyerabend, 2010, p. 364-365) ou "Brasil acima de tudo, Deus acima de todos”. ${ }^{6}$ Isto porque o regime político brasileiro, de acordo com a Constituição da República Federativa do Brasil de 1988, se consolida como ideal democrático na operacionalidade da governabilidade. Porém, quando se indaga "[...] quem pode falar e quem deve permanecer calado? Quem tem conhecimento e quem é apenas obstinado?” (Feyerabend, 2010, p. 365-366); uma resposta se sobressalta e toma a forma de uma organização piramidal "[...] com um líder no topo, que controla seus subordinados que por sua vez controlam os que estão mais abaixo” (Rogers, 1983 p. 245, tradução livre).

Portanto, é de suma importância a participação dos(as) estudantes nas aulas para que possam ser encorajados a apresentar suas visões sobre as temáticas em debate; respeitando-as e não as ridicularizando perante o saber especializado. É isso que Feyerabend defende no relativismo democrático - a causa de que “[...] todos têm o direito de dizer: olhem aqui, eu também sou humano; eu também tenho ideias, sonhos, sentimentos 
e desejos [...]" (Feyerabend, 2010, p. 365-366). O movimento contrário ao cientificismo (anticientificismo), por exemplo, poderia ter ganhado discussões e destaque em escalas menores se uma postura mais solidária, compreensiva e, sobretudo, humana por parte de "acadêmicos", "sábios", "peritos" e "experts" tivesse perseverado e se diálogos fossem possibilitados. "Devemos, pois, conservar-nos abertos para as opçóes, sem restringi-las de antemão" (Feyerabend, 1977, p. 22). Ademais, a própria questão de não se discutir, por vezes, na formação do(a) professor(a) de física questóes da e sobre ciência - não destacando sua "essência humana" -, também, pode ter se tornado um contribuinte para o alargamento do movimento supracitado.

Para o desenvolvimento de um ambiente receptivo a tais açóes deve-se deixar o(a) aluno(a) expressar, socializar, confrontar, deliberar, argumentar e comunicar seus próprios saberes da maneira que melhor lhe couber fazer, já que cada indivíduo reage e responde ao mundo com base em percepçóes e experiências distintas. A defesa pela diferenciação, que ecoa tanto em Rogers quanto em Feyerabend, contribui para a explicitação de outra implicação: a proficuidade de se utilizar várias formas de expressão (i.e., a pluralidade) que não meramente a maneira escrita visando ao formalismo matemático do conteúdo - no ensino de física. À título de exemplo, Silva, Costa e Samojeden (2018), ao utilizarem a abordagem rogeriana no contexto do PIBID-Física para o debate da eletrodinâmica, especificadamente, em duas turmas do ensino médio (regular e técnico) - com 18 alunos cada - do Colégio Maria Aguiar Teixeira em Curitiba/PR, ressaltam a prescindibilidade da multiplicidade de atividades e de recursos que se devem fazer disponíveis em "[...] uma sequência didática que [...] [contenha] abordagens teórico-expositivas, tecnológicas e experimentais na percepção do estudante em relação ao seu próprio aprendizado" (Ibid., p. 2, 2018).

Destaca-se, então, que há diversos modos de facilitar a aprendizagem, de aprender e de produzir conhecimento. Um viés histórico-filosófico e humanístico é uma escolha, dentre muitas outras. O ponderar sobre um entendimento acerca da construção e da comunicação de saberes que estejam em consonância com uma prática pedagógica e científica que valorize a imaginação, a criação, as diferenças, as divergências, as pluralidades, as variedades, os questionamentos, os argumentos, etc., possibilita uma maneira de revivescer uma educação e uma ciência mais humana e multifacetada. A inserção da interlocução de aspectos das abordagens educacionais de Rogers e epistemológica de Feyerabend em disciplinas voltadas a história da ciência e/ou a práxis pedagógica de professores(as) em cursos de licenciatura da área da física contribuem para as discussões esboçadas e podem ser pensadas para outros cenários da educação científica. Propostas mais concretas, pautadas na sugestiva ideia e nas condiçóes locais e reais de realização, podem ser aprofundadas e efetivadas.

\section{REFERÊNCIAS}

ABRAHÃO, L. H. de L. O Pluralismo global de Paul Feyerabend. 2015. 352 f. Tese (doutorado). Programa de Pós-graduação em filosofia, Universidade Federal de Minas Gerais, Faculdade de filosofia e ciências humanas. Belo Horizonte, 2015.

ALMEIDA, L. R. de. A psicologia de Carl Rogers na formação e atuação de orientadores educacionais. Revista de Educą̧ão PUC/Campinas, v. 23, n. 2, p. 311-327. 2018.

ASHTON, N. A. Rethinking epistemic relativism. Metaphilosophy, v. 50, n. 5, p. 587-607. 2019. http://dx.doi. org/10.1111/meta.12389.

AIRES, A. P. de O.; SILVA, E. F. G. da; BEZERRA, J. T. do V.; SANTANA, Z. dos S.; GUEDES, A. M. A. Implicaçôes da teoria humanista de Carl Rogers no processo de ensino e aprendizagem de física: um relato de experiência. Anais II CONEDU... Campina Grande: Realize Editora, 2015.

BRANCO, P. C. C.; CIRINO, S. D. Circulação de artigos brasileiros sobre Carl Rogers: ascensão, renascimento ou declínio? Revista Subjetividades, v. 17, n. 2, p. 1-11. 2017. http://dx.doi.org/10.5020/23590777.rs.v17i2.5789.

CAMPOS, R. F. Ética Contemporânea: os anos 60 e o projeto de psicologia humanista. Epistemo-somática, v. 3, n. 2, p. 242-260. 2006. 
DAMASIO, F; PEDUZZI, L. O. Q. O pior inimigo da ciência: procurando esclarecer questôes polêmicas da epistemologia de Paul Feyerabend na formação de professores. Investigaçôes em Ensino de Ciências, v. 20, n. 1, p. 97-126. 2015.

DAMASIO, F; PEDUZZI, L. O. Q. Considerações sobre a alcunha atribuída a Paul Feyerabend de "pior inimigo da ciência" e suas implicaçóes para o ensino de ciências. Alexandria: R. Educ. Ci. Tec., Florianópolis, v. 10, n. 1, p. 329-351. 2017. http://dx.doi.org/10.5007/1982-5153.2017v10n1p329.

DASEIN, B. M. Freedom to learn for the 21st century (education as if people mattered). 2018. 314f. Tese (doutorado). Programa de Pós-graduação em educação, University of Birmingham. Inglaterra, 2018.

FARRELL, R. P. Feyerabend and Scientific Values. In: Boston Studies in the Philosophy of Science. Vol. 235. Ed 1. Netherlands: Springer Science+Business Media Dordrecht. 2003. doi:10.1007/978-94-017-1542-3.

FEITOSA, E. A. L.; BRANCO, P. C. C.; VIEIRA, E. M. Notas sobre a visita de Carl Rogers ao Brasil: uma revolução silenciosa. Estudos e Pesquisas em Psicologia, v. 17, n. 2, p. 777-795. 2017.

FEYERABEND, P. K. Killing time: the autobiography of Paul Feyerabend. Chicago: University of Chicago Press, 1995.

FEYERABEND, P. K. Contra o Método. Trad. Octanny S. da Mata e Leonidas Hegenberg. Rio de Janeiro: Livraria Francisco Alves Editora S.A., 1977.

FEYERABEND, P. K. Knowledge, science, and relativism: philosophical papers. John Preston (ed.)., Vol 3. United Kingdom: Cambridge University Press, 1999.

FEYERABEND, P. K. Adeus à razão. São Paulo: Editora UNESP, 2010.

FORATO, T. C. de M.; PIETROCOLA, M.; MARTINS, R. de A. Historiografia e natureza da ciência na sala de aula. Caderno Brasileiro de Ensino de Física, v. 28, n. 1, p. 27-59.2011. http://dx.doi.org/10.5007/2175-7941.2011v28n1p27.

GANHOR, J. P.; JESUSA, A. J. B. de; MEGLHIORATTI, F. A. Mobilizações de perspectivas de Paul Feyerabend na pesquisa em educação em ciências. Amazônia - Revista de Educação em Ciênciase Matemática, v.16, n. 37, p. 54-72. 2020.

GOLL, C. K. C.; MELLER, J. K.; WITT, D. T.; PEREIRA, K.; KEMCZINSKI, A.; COMIOTTO, T. Anarquismo Metodológico de Paul Feyerabend: abordagens na Ciência. Revista Thema, v. 15, n. 2, p. 539-552. 2018.

LIMA, L. D. de; BARBOSA, Z. C. L.; PEIXOTO, S. P. L. Teoria humanista: Carl Rogers e a educação. Caderno de Graduação - Ciências Humanas e Sociais, Alagoas, v. 4. n.3, p. 161-17. 2018.

LOPES, J. C. Educação centrada em estudantes de licenciaturas: um processo de tornar-se docente. 2020. 193 f., il. Tese (doutorado). Programa de Pós-graduação em Processos de Desenvolvimento Humano e Saúde, Universidade de Brasília, Brasília, 2020.

KIRSCHENBAUM, H. Carl Rogers's life and work: an assessment on the 100th anniversary of his birth. Journal of Counseling and Development: JCD, v. 82, n. 1, p. 116-124. 2004.

KIRSCHENBAUM, H. The life and work of Carl Rogers. Alexandria, VA, US: American Counseling Association; Ross-on-Wye, England: PCCS Books, 2007.

KIRSCHENBAUM,H.;JOURDAN, A. The currentstatus of Carl Rogers and the person-centered approach. Psychotherapy: Theory, Research, Practice, Training, v. 42, n. 1, p. 37-51. 2005. http://dx.doi.org/10.1037/0033-3204.42.1.37.

KAMPOURAKIS, K. History and philosophy of science courses for science students. Science E̊ Education, v. 26, n. 6, p. 611-612. 2017.

KUSCH, M. Relativism in Feyerabend's later writings. Studies In History And Pbilosophy Of Science Part A, v. 57, s/n, p. 106-113. 2016.

MATIAS, E. de L.; LACERDA, R. G. de; OLIVEIRA, C. A. de; RODRIGUES, A. de C. F. A Contribuição da Teoria Humanista para a Formação Integral do Aluno. Revista Semiárido De Visu, v. 7, n. 2, p. 242-251. 2019.

MCBRIDE, B. B.; BREWER, C. A.; BRICKER, M.; MACHURA, M. Training the next generation of renaissance scientists: the GK-12 ecologists, educators, and schools program at the University of Montana. Bioscience, v. 61, n. 6, p. 466-476. 2011. 
MILLER, R. B. Making Scientific Americans: Identifying and educating future scientists and nonscientists in the early twentieth century. 2017. 290f. Tese (doutorado). Programa de Pós-graduação em educação, Harvard Graduate School of Education. Estados Unidos, 2017.

MOREIRA, M. A. Teorias de aprendizagem. 2a ed. São Paulo: EPU, 2011.

OlIVEIRA, D. G. S. Anarquismo, Autonomia e Objetivo no Ensino das Ciências. 2017. 218f. Tese (Doutorado). Programa de Pós-graduação em Ensino, Filosofia e História das Ciências, Universidade Federal da Bahia e Universidade Estadual de Feira de Santana-UEFS. Salvador. 2017.

RAICIK, A.C.; PEDUZZI, L. O. Q.; ANGOTTI, J. A. P. A estrutura conceitual e epistemológica de uma controvérsia científica: implicaçôes para o ensino de ciências. Experiências em Ensino de Ciências, v.13, n.1, p. 42-62. 2018.

RÉGIO, J. Cântico negro. In: RÉGIO, J. Poemas de deus e do diabo. 4. ed. Lisboa, PT: Portugália, p. 108-110. 1955.

ROGERS, C. R. Freedom to learn for the 80's. Columbus, Ohio: Charles E. Merrill Publishing Company, 1983.

ROGERS, C. R. Liberdade para aprender: uma visão sobre o que a educação pode ser. Belo Horizonte: Interlivros, 1978.

ROGERS, C. R. This is Me, 1961. P. 6-29. In: The Carl Rogers Reader. (Org)edited by Howard Kirschenbaum and Valerie Land Henderson. Boston, NY, MA: Houghton Mifflin Company, 1989.

ROGERS, C. R. 'Significant learning: in therapy and in education', Educational Leadership, v.16, n. 4, p. 232-242. 1959.

SANTOS, H. S. T. dos; FUSINATO, P. A.; GARDELLI, D. O Anarquismo epistemológico e o ensino de física: implicações da epistemologia de Paul Feyerabend no ensino. E-boletim da Física, v. 7, n. 3, p. 1-4. 2018.

SENA JÚNIOR, C. Obscurantismo e anticientificismo no Brasil bolsonarista: anotações sobre a investida protofascista contra a inteligência e a ciência no Brasil. Cadernos Do GPOSSHE On-Line, v. 2, n. especial, p. 21-49. 2019.

SILVA, A. E. da; COSTA, J. F. da; SAMOJEDEN, L. L. Aprendizagem centrada no estudante mediada por TICs no PIBID-FÍSICA. Anais Congresso Internacional de Educação e Tecnologias (CIET) e Encontro de pesquisadores em Educação a distância (EnPED)... São Carlos, maio 2018. ISSN 2316-8722. Disponível em: <https://cietenped.ufscar. br/submissao/index.php/2018/article/view/48>. Acesso em: 17 jul. 2021.

SILVA, A. S. S. A (In)visibilidade de Paul Feyerabend nas publicaçôes sobre o Ensino de Ciências no Brasil. 2016. 966. Dissertação (Mestrado). Programa de Pós-Graduação em Ensino de Ciências e Matemática, Universidade Federal de Goiás. Goiás 2016.

SOBREIRA, M. do C.; TASSIGNY, M. M.; BIZARRIA, F. P. de A.. O “ser" e o "fazer" docente no ensino superior na perspectiva do legado de Carl Rogers. Educação, Ciência e Cultura, v. 21, n. 1, p. 117-127. 2016.

\section{NOTAS}

1 “[...] a liberdade de que falo é coisa essencialmente interior, algo que existe na pessoa viva, inteiramente à parte de qualquer das escolhas externas de alternativas em que tantas vezes supomos consistir a liberdade” (Rogers, 1983, p. 253).

2 Rogers publicou sua mais importante autobiografia sob o título This is me (Esse sou eu) em 1961.

3 Feyerabend completou sua biografia intitulada Killing time (Matando o tempo) em seu último mês de vida no ano de 1994.

4 Disponível em: <https://www.ifrdp.com/evenements/>. Acesso em: 17 jul. 2021.

5 A titulação de "anarquista" atribuída à Feyerabend lhe foi inicialmente cunhada por seu inestimável amigo húngaro Imre Lakatos (1922-1974), um filósofo da matemática e da ciência, racionalista e admirador de Karl R. Popper (1902-1994). Feyerabend, contudo, faz a ressalva de que não é condescendente com um "anarquismo político" que se opóe à ordem de todas as coisas estabelecidas na perspectiva de serem consideradas como corrompidas, irreais, efêmeras e vazias de importância e de significado. "Esse [tipo de] anarquismo religioso ou escatológico nega não apenas as leis sociais, mas as leis morais, 
físicas e perceptivas [...]” (Feyerabend, 1977, p. 290). Assim, o anarquismo epistemológico, do qual Feyerabend se declara participante, reconhece a limitação de regras, procedimentos e padróes, mas não sustenta que sem eles se deva proceder.

6 Slogan da campanha que elegeu Jair Messias Bolsonaro em 2018 para representante do Brasil; um país laico.

\section{Letícia Jorge}

Doutoranda do Programa de Pós-Graduação em Educação Científica e Tecnológica

Universidade Federal de Santa Catarina

Campus Universitário Trindade, Florianópolis, SC, Brasil.

E-mail: leticiajorgeifsc@gmail.com

\section{Luiz O. Q. Peduzzi}

Professor Doutor do Programa de Pós-Graduação em Educação Científica e Tecnológica

Universidade Federal de Santa Catarina

Campus Universitário Trindade, Florianópolis, SC, Brasil.

E-mail: luizpeduzzi@gmail.com

Contato:

Campus Universitário Reitor João David Ferreira Lima - Trindade

Florianópolis - SC | Brasil

CEP 88.040-900

Editor responsável:

Guilherme Trópia Barreto Andrade 